\title{
Challenging the addiction/health binary with assemblage thinking: An analysis of consumer accounts
}

David Moore $^{1^{*}}$, Kiran Pienaar ${ }^{1}$, Ella Dilkes-Frayne ${ }^{2} \&$ Suzanne Fraser ${ }^{1}$

\section{* Corresponding author}

E: d.moore@curtin.edu.au

T: +61390792203

1. National Drug Research Institute, Faculty of Health Sciences, Curtin University, NDRI Melbourne Office, 6/19-35 Gertrude St, Fitzroy, Victoria, 3065, Australia

2. Social Studies in Health and Medicine Research Program, Arts, Monash University, Menzies Building, 20 Chancellors Walk, Clayton Campus, Victoria, 3800, Australia

\section{Acknowledgements}

The research reported in this paper was conducted by researchers from Curtin University's National Drug Research Institute (NDRI), in collaboration with Healthtalk Australia, Monash University and the University of New South Wales' Centre for Social Research in Health, and funded by Australian Research Council Discovery grant (DP140100996). Suzanne Fraser is funded by an Australian Research Council Future Fellowship (FT120100215). The National Drug Research Institute at Curtin University is supported by funding from the Australian Government under the Substance Misuse Prevention and Service Improvement Grants Fund. The authors thank the participants for generously sharing their stories. They also thank the reviewers and associate editor for their comments on an earlier version of this piece. 


\title{
Challenging the addiction/health binary with assemblage thinking: An analysis of consumer accounts
}

\section{Keywords}

Addiction, health, assemblage, critical analysis, qualitative research, Australia

\begin{abstract}
Critical analyses of drug use and 'addiction' have identified a series of binary oppositions between addiction and free will, independence, self-control, responsibility, productivity and autonomy. This critical work has also examined how science, policy and popular discourses frequently characterise addiction as antithetical to health and well-being. Furthermore, those diagnosed with addiction are often understood as indifferent to health and well-being, or as lacking the knowledge or desire required to maintain them. In this article, we draw on data from 60 qualitative interviews with people who self-identify as living with an 'addiction', 'dependence' or 'habit', to argue that the binary opposition between addiction and health struggles to attend to their rich and varied health perspectives and experiences. We explore three themes in the interview data: reinscribing the binary opposition between addiction and health/well-being; strategies for maintaining health and well-being alongside addiction; and alcohol and other drug consumption as aiding health and well-being. Perhaps because addiction and health have been so thoroughly understood as antithetical, such perspectives and experiences have received surprisingly little research and policy attention. Yet they offer fertile ground for rethinking the strengths and capacities of those who self-identity as living with an addiction, dependence or habit, as well as untapped resources for responding to the harm sometimes associated with alcohol and other drug use.
\end{abstract}




\section{Introduction}

An extensive body of sociological research has identified the political, ideological and symbolic role of health in the management of contemporary societies as well as the governing obligation of modern citizens to embrace and pursue health. These issues have informed critical analyses of drug use and 'addiction', which have identified a series of binary oppositions between addiction and free will, independence, self-control, responsibility, productivity and autonomy. This critical work has also examined how science, policy and popular discourses frequently characterise addiction as antithetical to health and well-being. Furthermore, those diagnosed with addiction are often understood as indifferent to health and well-being, or as lacking the knowledge or desire required to maintain them. In this article, we draw on data from 60 qualitative interviews with people who self-identify as living with an 'addiction', 'dependence' or 'habit', to argue that the binary opposition between addiction and health struggles to attend to their rich and varied health perspectives and experiences. We explore three themes in the interview data: reinscribing the binary opposition between addiction and health/well-being; strategies for maintaining health and well-being alongside addiction; and consumption as aiding health and well-being. Perhaps because addiction and health have been so thoroughly understood as antithetical, such perspectives and experiences have received surprisingly little research and policy attention. Yet they offer fertile ground for rethinking the strengths and capacities of those who self-identity as living with an addiction, dependence or habit, as well as untapped resources for responding to the harm sometimes associated with alcohol and other drug use. In the next sections, we review critical literature that attends to the binary between addiction and health evident in science, policy and popular discourses; outline our theoretical approach; and detail our interview methods. 
We then analyse the qualitative material generated by the in-depth interviews and discuss the implications of our analysis for future policy.

\section{Background}

The political, ideological and symbolic role of health in the governing of contemporary societies and citizens has been the subject of sustained sociological analysis (e.g. Crawford, 1977, 1994, 2006). Poststructuralist accounts have analysed how the promotion of health in policy and practice has become the basis for 'technologies of the self' in neo-liberal societies, creating obligations on the part of individuals to lead 'healthy' lifestyles (e.g. Burrows, Nettleton \& Bunton, 1995; Lupton, 1995; Petersen, 1997; Petersen \& Bunton, 1997; Petersen \& Lupton, 1996). Those unwilling or unable to meet the obligation to pursue and achieve health fail the test of modern citizenship, and this has material implications for access to the rights and rewards attendant on citizenship status (e.g. Fraser \& Seear, 2011; Fraser \& valentine, 2008; Pienaar, 2016; Squire, 2010). However, the widespread deployment of notions of 'health' in the governing of populations also conceals 'value judgments, hierarchies, and blind assumptions that speak as much about power and privilege as they do about well-being' (Metzl, 2010:1-2; Tesh, 1990). 'Health', that is, involves a 'false neutrality' (Kirkland, 2010:198), and 'appealing to health' introduces 'a set of moral assumptions that are allowed to fly stealthily under the radar' (Metzl, 2010:2).

The governing obligation of modern neo-liberal citizens to embrace and pursue health and all it entails has also been taken up in critical analyses of drug use and addiction. Encompassing historical, sociological and poststructuralist approaches, these works have identified a series of taken-for-granted binary oppositions between addiction and modernity's valorised attributes and capacities: free will, independence, self-control, responsibility, productivity 
and autonomy (e.g. Fraser \& Moore, 2008; Keane, 2002; Levine, 1978; Moore, 2004; Moore \& Fraser, 2006; O’Malley, 1999; Redfield \& Brodie, 2002; Reinarman, 2005; Reith, 2004; Room, 1985, 2003; Seddon, 2010; Sedgwick, 1993; Valverde, 1998). Of most relevance here is Keane's (2002) identification of a series of closely related binary oppositions in medical, pharmacological and popular discourse on drug and other addictions: health/addiction, order/disorder, normality/pathology, good/evil and natural/artificial. Building on earlier sociological accounts of the role of health promotion in creating binaries between health and a pathologised other, Keane highlights how the rise of neuroscience has provided new ways of reinscribing these oppositions. As she (2002:26) argues, in one of the earliest critical studies of neuroscience, images of brain scans 'construct a simple and clear-cut visual distinction between health and disease', between 'healthy brains' and 'addicted brains' (see also Dumit, 2004). In a more recent critical analysis of science, policy and popular discourses, Fraser et al. (2014) identify a series of related binary oppositions contrasting the 'disease' or 'disorder' of addiction with health. For example, in two of the major contemporary scientific and clinical approaches to addiction, the brain disease model and the DSM-5:

The addicted individual is [...] realised as a target for particular forms of regulation and intervention in order to restore the idealised state of autonomy, control and productivity reified as normal and healthy existence. (Fraser et al., 2014:58, emphasis added)

This critical literature identifies the persistence in science, policy and public discourses of a binary opposition between addiction and health as well as a series of closely related binaries: pathology/normality, compulsion/freedom, disorder/order, disease/health. But how well do such binaries map onto the accounts and experiences of those who live under the sign of 'addiction'? As we show, these binaries struggle to attend to the rich and varied health 
perspectives and experiences of those who self-identify as living with an addiction, dependence or habit. Perhaps because addiction and health have been so thoroughly understood as antithetical, such perspectives and experiences have received surprisingly little research and policy attention (Weinberg, 2011).

\section{Approach}

The approach to 'addiction' and 'health' we adopt in this article draws on the critical literature cited above. In this respect (as well as others), it differs from the accounts conventionally offered by neuroscience and psychology, which treat addiction 'as a more or less established medical fact, and like all medical facts, it is understood as pre-existing its “discovery” by medical science’ (Fraser \& Moore, 2011:6). Rather than understanding addiction as a unified anterior object located within an individual subject, we employ Fraser et al.'s relational definition of addiction as an 'assemblage':

the assemblage can be seen as an ad hoc cluster of knowledges, technologies, bodies and practices that contingently gather to form a temporary phenomenon, be it abstract or material. The world is made up of such assemblages, not of stable natural objects or self-evident, foundational concepts. One of these assemblages is [...] addiction. (2014:19)

Furthermore, the addiction assemblage is:

made in practice and - an effect of politics - it is multiple and contingent, its shape, scale and content dependent upon a range of other equally labile phenomena. (Fraser et al., 2014:235-6)

The many and varied practices engaged in ongoing attempts to stabilise particular versions of addiction (to drugs but also to food, sex, love, the internet and so on) in specific ways and under specific circumstances (e.g. in genetics, neuroscience, psychiatry, self-help literature) 
constitute an 'epidemic of addicting' (Fraser et al., 2014:236). Building on Sedgwick's (1993) observation that an 'epidemic of addiction attribution' is underway in contemporary Western societies, the term 'addicting' refers here to an active, emergent process that merits critical scholarly investigation.

Likewise, we approach 'health' as an assemblage. In an analysis that shares the relational ontology of Fraser at al.’s approach to addiction assemblages, Duff advocates:

a posthuman account of health, more attentive to the imbrications of matter, affect, biology, technology and politics that characterise so much of contemporary life (Rose 2007). If health may no longer be taken to be the preserve of a discrete biological agent - if it must instead be distributed among an assembled throng of human and nonhuman forces - then health should be regarded, in its turn, as a relational achievement, as the effect of bodies acting together in force and sympathy. (Duff, 2014:185)

To operationalise this vision of health as an assemblage, Duff calls for 'renewed attention to the real experience of health and illness, and renewed focus on the spaces, bodies, forces, affects and relations active in each event of health and illness' (2014:199; for other accounts of alcohol and other drug-related health and harm assemblages, see Farrugia, 2015; Hart, 2015; McLeod, 2014; Race, 2014). In the analysis that follows, we attend carefully to the assemblages articulated by the research participants and in particular to the varied entanglements of addiction and health evident in them.

\section{Method}

The qualitative research project on which this article is based involved a collaboration with Healthtalk Australia (http://healthtalkaustralia.org), an Australian research consortium that conducts qualitative research into personal experiences of health and illness, and was 
designed to gather personal accounts of drug use for editing and collecting in a web-based resource on addiction (www.livesofsubstance.org). Healthtalk Australia collaborative projects use a research methodology developed by Oxford University’s Health Experiences Research Group (HERG, 2010), which involves collecting and analysing the health experiences of a diverse range of people and presenting these in carefully curated online resources. Following this methodology, purposive sampling and in-depth qualitative interviewing were used to collect accounts from a diverse range of people $(\mathrm{N}=60)$ who responded to a recruitment flyer that opened with the question: 'Do you consider yourself to have a drug habit, dependence or addiction?' The flyer was circulated through alcohol and other drug sector newsletters, treatment services, community noticeboards, social media and drug user organisations. Those who responded to the recruitment flyer were screened to ensure that we recruited participants with a pattern of consumption that would qualify them for a diagnosis of 'substance use disorder' or 'dependence syndrome', the terms for 'addiction' in two influential diagnostic instruments, namely the DSM-5 (American Psychiatric Association, 2013) and the ICD-10 (World Health Organization, 1992). Asked to describe their consumption and what made them think they were experiencing an addiction, dependence or habit, participants referenced ideas that align with standard addiction diagnostic criteria such as 'a strong desire or sense of compulsion' to take the drug, 'difficulties controlling substance-taking behaviour', 'taking it in larger amounts than intended', 'withdrawal', 'evidence of tolerance' and continuing use 'despite clear evidence of overtly harmful consequences'. ${ }^{1}$ Respondents were identified as eligible to participate if they referenced three or more of the $D S M-5$ or $I C D-10$ criteria, which would qualify them for a diagnosis of 'substance use disorder' in DSM-5 nomenclature or 'dependence syndrome' in ICD-10 terms.

\footnotetext{
${ }^{1}$ While these criteria are generally considered to be objective measures of pathology, they are context dependent, and rely on the assessment of self-reported behaviour and culturally specific social norms (Keane, 2002; Fraser et al., 2014; Dwyer \& Fraser, 2016).
} 
Those selected for interview described ongoing $(n=47)$ or past regular use $(n=13)$ of a range of drugs including alcohol, cannabis, crystal methamphetamine, heroin, prescription and over-the-counter drugs (e.g. benzodiazepines, codeine) and 'party drugs' (e.g. MDMA, GHB, ketamine). While many had experience of treatment programs, we also interviewed several people who had neither participated in such programs nor accessed any services. Detailed information about the people interviewed is presented in Appendix 1. The study was approved by Curtin University's Human Research Ethics Committee (HR 55/2014). All participants provided informed written consent. To protect participant identities, each was given a pseudonym and all identifying details were removed from the transcripts.

Interviews took place in urban and regional Victoria and New South Wales, Australia. Following an open-ended invitation to 'tell us their story', participants were asked about their experiences of living with an addiction, dependence or habit, including how consumption fits into daily life, experiences of treatment, and future plans. The opening invitation and relatively unstructured interview guide reflected our intention to approach participants as whole, complex people with rich, textured lives, and this is reflected in the interview transcripts. Consistent with common research practice in the Australian context, participants were reimbursed $\$ 50$ for their time (Fry \& Dwyer, 2000). All interviews were conducted in person (by authors KP and EDF, and project research staff Jeanne Ellard and Jamee Newland) and were audio-recorded and transcribed verbatim.

The interviews were analysed using an iterative inductive approach in which a preliminary list of codes was drawn up based on themes emerging from the data, as well as knowledge of key debates and past research on addiction. This list was refined in consultation with the 
research project team and advisory panel, which consisted of representatives from policy, service provision and consumer advocacy groups. The data were then coded with the aid of the NVivo qualitative data management software. This article focuses on thematic codes relating to consumption and health practices.

Health and well-being are key concerns for many research participants but their complex relationships with addiction were expressed in a variety of ways. In the next sections, we explore three themes in the interview data: reinscribing the binary opposition between addiction and health/well-being; strategies for maintaining health and well-being alongside addiction; and consumption as aiding health and well-being.

\section{Reinscribing the binary opposition}

Some participants articulated the relationship between addiction, health and well-being in terms strikingly reminiscent of the binary opposition documented in existing sociological analyses of science, policy and public discourses: that addiction is antithetical to health. For example, Renee (F, 35, works in hospitality) was, at the time of her interview, living in a residential treatment unit after completing a custodial sentence. Describing herself as now 'in recovery', she said her past crystal methamphetamine use had initially provided a sense of balance but she had now come to understand it as 'out of control'. For Renee, '[a]ddiction, [it] doesn't matter what sort of addiction, an addiction is really unhealthy'.

Other participants offered similar views on the incompatibility of heavy drinking and health. For example, in his interview, Angelo (M, 35, works in construction) recounted a troubled history with alcohol, including violence and drink-driving and other offences. Following the break-up of a relationship a few months prior to his interview, which he attributed to his 
drinking, Angelo had come to see it as a 'problem' and a 'bad habit' that he would need to address in order to maintain his health and well-being:

I think for my overall health and well-being, it's better to not have any alcohol at all [...] I want to be able to say, 'Hey, I don't drink' and not feel bad about that, and not have a secret drinking problem or something like that.

Another participant, Dawn (F, 38, unemployed), interviewed in a residential treatment centre, spoke about her 'recovery' from alcohol addiction in the following terms:

I've got to be honest, I really am going to miss alcohol. It's been part of me for so long, [and] even though I felt like it was my friend, it really wasn't. But on the recovery side it's great. I mean, just to be able to be sober and live my life without alcohol in my system and to be able to say, be real and be that person, be me, without alcohol, because that helped me a lot too in social situations, the alcohol. I could come out and have the fake confidence. But yeah, that'll be great [being sober] - healthwise, mentally, physically. But I really am scared to be without it.

For Dawn, when alcohol had been 'part of [her]', it had resulted in the inauthenticity of 'fake confidence' and a false perception of friendship. Now in 'recovery', and drawing on its emphasis on abstinence and the transformation of identity (Keane, 2000), she is 'scared to be without it' but articulates a desire to expunge alcohol from her life in order to be authentically 'real' and to achieve optimal physical and mental health and well-being.

Other participants, in reinscribing the binary opposition between addiction and health, emphasised different concerns. Lala (F, 35, works in health), for instance, positioned her cannabis 'dependence' as unhealthy, but on grounds different from those articulated by Dawn: 
I think for me the [cannabis] smoking is probably my biggest health issue or my biggest thing in my life that [...] makes me think, 'what are you doing?' Like, 'what's this about? Why all this energy towards this? What about the other things in your life? What a waste of money, what a waste of time, what a waste of consciousness, like, what the fuck', you know? I would say it's my major health issue.

For Lala, the personal, financial, temporal and experiential resources required to sustain her cannabis use compromise her health.

Our final example of participant accounts that reinscribe the binary opposition between addiction and health is provided by Zoe (F, 30, studying), who described herself as an 'addict for life'. Reflecting on her experience of 'detox' and 'recovery' from crystal methamphetamine addiction following the removal of her children from her care, she said: I was there [in detox] for seven days and because I'd [already] started to cut back myself [before entering detox], I think my recovery was a lot better because I was already in the mind frame of 'I want to get off this. I want to be good again. I want to be healthy and have my kids back and have [a] proper life again, have a future', because I realised I was pretty well slowly killing myself [...] I was using daily and I was using a lot.

There is much to note in Zoe's account, which references several valorised sentiments and ambitions. For her, taking crystal methamphetamine is at odds with being 'good' and 'healthy', living 'properly', being a parent and forging a future.

The assemblages of alcohol and other drug use and addiction articulated by Renee, Angelo, Dawn, Lala and Zoe include legal problems, relationship struggles, inauthentic subjectivity, misallocation of money and other resources, and state intervention in child custody. In each 
case, health - whether defined in social, physical or psychological terms - is framed as other to consumption: being addicted means being unhealthy; pursuing and achieving health requires the cessation of use. However, other participants, while also sometimes referencing this opposition, offered accounts that emphasise a more complex set of relations between addiction, health and well-being.

\section{Strategies for maintaining health and well-being}

Many participants described strategies for maintaining health and well-being while continuing to use drugs in ways that they themselves understood in terms of addiction, dependence or habit. We draw attention to the ways in which these accounts include addiction and health within the same assemblage. For example, Scarlett (F, 29, works in finance) had previously taken crystal methamphetamine at work and on weekends but now limited herself to injecting the drug on weekends with her partner. She expressed a desire to reduce her use further in order to resume regular contact with her family and to start one of her own. She had yet to try drug treatment but had considered 'recovery' or, alternatively, pharmacotherapy (Modafinil), as possible treatments for her crystal methamphetamine 'habit'. Referencing the binary opposition of addiction/health, Scarlett said that she and her partner 'want to maintain our healthy lifestyle without using drugs' and that she would like to 'stop using so [I] can get healthy'. However, while Scarlett contemplated ways of reducing and eventually ceasing her crystal methamphetamine use, she also offered a complex account of balancing her use with full-time work commitments:

[D]uring the week I just eat and sleep as much as I can. I do go to the gym. I take yoga classes as well [...] I try to be as healthy as possible, and it sucks I can't be healthy and maintain [regular crystal methamphetamine use] as well because [my boyfriend and I] do love getting out and going for jogs at 6 o'clock in the morning when we're not using 
[crystal methamphetamine]. So [after using crystal methamphetamine on the weekend] we'll get to [...] Tuesday after we've had a good sleep, and we just get up and go for a walk in the morning before work and that's very nice. We'd have a nice breakfast and we plan lunches.

The addiction assemblage articulated by Scarlett includes the separation of her crystal methamphetamine habit from work settings and the health-promoting activities she pursues in her leisure time, which work as strategies for maintaining her health alongside her consumption. Although it could be argued that this separation reinforces the binary opposition between health and 'addiction', Scarlett's account does not require the renunciation of drug use in order to pursue health. Instead, and in contrast to the previous accounts, she articulates addiction and health as co-existing, rather than antithetical phenomena.

In his interview, Harry (M, 52, works in the arts), who has extensive experience of heroin, cannabis, alcohol and amphetamine use, described an assemblage that includes drugs, work and health. One of his strategies for maintaining health is to take breaks from regular use every so often in order to 'recover':

After a while speed will wear you down, particularly if you're doing the sort of work I do, which is shift work, which can constitute like 70-, 80-hour weeks and stuff like that. It's very convenient, a very useful drug in that regard $[\ldots]$ But at the same time, it will bugger you over a period of time. You know, it's one of those drugs you really need to take a break [from]. I guess it's like alcohol. You know, one of the tricks of alcohol is to give your liver a rest. Sure, get drunk that night, but don't then get drunk the next night, the next night, the next night, because you will be fucked at the end of that. 
For Harry, taking a break from speed allowed him to manage long-term, heavy consumption without significant negative impacts on his health.

Maintaining good physical health while using drugs regularly was also important to Artemis (M, 28, works in education), who, at the time of interview, smoked cannabis most evenings and used MDMA, GHB, cocaine, and less often crystal methamphetamine, on weekends. Resistant to the concept of 'addiction' as a descriptor for his drug use and preferring the term 'lifestyle', Artemis described his health strategies in the following way:

I actually think, again, this is going to sound fairly wanky, but I'm in quite good physical health. I go to the gym five days a week, as every gay man in [this city] is expected to do. I have endurance, I run, I cycle, I play tennis regularly, I swim [...] I know the best thing I can do for my brain is to keep my body as healthy as possible [...] The thing that is probably most detrimental to my health when I take drugs is the fact that I chain smoke when I'm high.

Artemis saw his occasional 'chain smoking' as a side-effect of his other drug consumption, and a greater impediment to his health than his party drug use per se. However, with the inclusion of other activities in his 'lifestyle' alongside drug use, he said he still met common markers of 'good physical health'.

Like Artemis, Lucy (F, 34, studying) articulated an addiction assemblage that includes a range of strategies to enhance physical and mental health and well-being alongside a cannabis 'habit'. When she was younger, she had tried many different drugs while participating in the 'party scene' but now restricted herself to daily cannabis smoking, after her family had gone to bed, during what she described as 'my time'. Lucy took the following steps to maintain health and well-being: 
I write, I play netball, I walk all the time, walk my dog. I'm pretty active. Yeah, I like to go bush walking. [...] I used to be really lazy but I definitely eat better now, because I mean, I'm getting older. You['ve] got to be more conscious of these things. So yeah, I eat pretty well, and I'm starting to really take an interest in growing my own food and buying organic food, things like that. I sometimes do meditation at the local Buddhist centre, because I know that's good for me, because I do tend to get a bit frazzled [laughs]. Sometimes, when everything is going on, it's nice to relax. Yeah, so lots of stuff really.

Zac (M, 53, works in health) is a highly-educated gay man who takes pride in his health and fitness. During his thirties and forties, he had consumed crystal methamphetamine, GHB, cocaine and MDMA when going clubbing. Zac sought counselling during a period in which he took drugs 'a bit too often' and now restricts his crystal methamphetamine and GHB use to 'chemsex', describing himself as 'dependent on drugs in sexual and party scenarios'. Like Artemis and Lucy, the addiction assemblage articulated by Zac included exercise but he also added another element, an active social life, which helped him to manage his drug consumption:

You know, [taking drugs] is a fun, great thing to do but I love just having dinners with my friends [...] I like exercising, I like cycling. [There are] a million other things I want in my life, and I think that's why [taking drugs] hasn't become dangerous for me because I have lots of other interests. It's just a part of me, but it's not my whole life [...] I mean next weekend I have arrangements with friends: literally lunch, dinner the whole weekend so there's no space for [taking drugs] [...] The other thing is, the more stuff I have going on, and the more interests and fun things I'm doing, the less I have time [to take drugs] and [the] less I have an interest in doing it. So these are all [...] 
systems of control [...] I can say now that that's part of my strategy here [in Australia] of avoiding it [...] I think it's a good strategy, and I have no problem with it, because it has a really good, healthy side-effect [of] having a good life.

By increasing the range of other physical and social activities he was involved in on weekends, Zac was able to both manage his crystal methamphetamine and GHB consumption and work to maintain his health.

There are certainly echoes of the binary opposition between addiction and health in the accounts of Scarlett, Harry, Artemis, Lucy and Zac, and some expressed a desire to reduce or cease use altogether. But they also constitute addiction as an assemblage that includes strategies for achieving health and well-being alongside regular use: following dietary, sleeping and exercise regimens; balancing work routines and use; identifying personal role models and setting goals; maintaining social relationships and pursuing a range of personal interests.

\section{Alcohol and other drug use as aiding health and well-being}

In the previous section, we considered accounts in which participants describe their strategies for managing or supporting their physical and mental health alongside their use of alcohol and other drugs. In this section, we consider participant accounts in which consumption is constituted in the assemblage as a force active in the maintenance of health and well-being. Our first example is provided by Zadie (F, 33, works in health), who had prior experience of detoxification for heroin use and had developed several strategies for managing her current heroin 'dependence': not having a partner who used opiates, not having dealers' numbers in her phone, and alternating her heroin use with use of other drugs such as crystal methamphetamine, LSD and ketamine. When she wanted a break from heroin use, she would 
take time off work and spend it at a friend's home. Zadie also explained that she consciously 'works on' her mental health by dedicating time for it, undertaking activities that she enjoys and setting personal goals:

I like to look after myself, my physical health and my mental health. And I know what works for me [...] I know when I need to spoil myself and go buy some great new clothes, and I know when I need to just take myself bush [leave the city] and turn the phone off for four days, and I know when I need to just take a break from reality and go tripping [laughs] or have a nice, relaxed, fluffy week on heroin. I actually see that, for me, as a part of my self-care for my physical and mental health, you know, because the tension of life and everything can just build up otherwise [...] I read books, I came up with strategies, I kind of pinpointed people in my life that seemed to have really great mental health, and tried to figure out what and how and why they've got there, and I really dedicated a lot of time to it. You know, I came up with all sorts of strategies, and set little goals for myself [...] You know, kind of put down on paper what kind of person I wanted to be, and I just worked out ways to get there, and it took maybe three years, but I got there, and I've been there ever since. (emphasis added)

Here, 'tripping' and heroin consumption feature in the wide range of strategies Zadie uses to actively support her health and well-being.

Our next example is provided by Nadia (F, 32, not working due to injury). In her interview, Nadia spoke of her previous cannabis 'addiction', use of anti-depressants, counselling, detoxification, and use of the psychedelic dimethyltryptamine before ceasing drug use altogether (with the exception of cigarettes). However, following a back injury sustained in a work accident, she now suffers from chronic back pain and is 'dependent' on prescription 
drugs Valium (diazepam) and Endone (oxycodone hydrochloride). Like some of the participants in the previous section, Nadia regarded having a good diet, adequate sleep and low-stress work environment as crucial to her health, but also emphasised the role of prescription drugs in managing her chronic back pain:

I believe I'm doing everything I can for good healthcare. I believe that diet is extremely important, and it's at the forefront of everything. Also, good sleeping patterns is something else that's massively important. If you don't get up at a reasonable hour, and that includes weekends, and if you go to bed too late, how are you ever expected to be in good health? You're not [...] I believe that it's vital [for] someone with a bad back, because $[\ldots]$ you're putting so much filth and rotting out your body with this toxic stuff [prescribed opioids]. It's important to keep your body as pure as possible [...] It's also important to keep your environment and your life as stress-free as possible [...] I found that when I look after myself, and I don't work in jobs where people are draining my energy all the time and being just bullies, then my spine is in much better health, and I have more energy for myself and my [children]. Yeah, but I do believe that taking these pharmaceutical medications. They're invented for a reason and this is probably the reason $[\ldots]$ These drugs were made for me and people like me.

Nadia's account is complex: she emphasises the role of prescription drugs in managing her back pain (and thus helping her maintain her health and well-being), while also reinforcing notions of the healthy body as 'pure' and 'natural', unadulterated by artificial drugs.

Along with her use of Valium and Endone, Nadia, like several other participants, also included in the addiction assemblage she articulated alternative therapies to manage her chronic back pain, enhance her well-being and enable her to function effectively: 
The yoga supports me through [the pain]. If I didn't have that, I'd be in pretty bad shape. But yeah, it supports me through it. I can't do all the fancy [yoga positions] any more, but it's still [....] really good to have that tool for healing [...] You know, I put up with [the back pain] to a certain extent. Sometimes if I've had too many [Endone], or if [taking Endone] can be avoided by lying down instead, because a lot of the time, you might have excruciating pain, but you can get to the end of the day, [you manage to] go to bed [without taking it]. But if it's 10am, you're better off to just take one [Endone], or take half of one, or just do something, you know. So you try everything else first and that's sort of like the last option that I take [...] I feel that [I've achieved] a nice balance between [taking prescribed drugs] and holistic things like acupuncture and Reiki and strengthening exercises. Yeah, because I've got it all happening, it's good [...] I do about two hours' worth of yoga, meditation, Reiki. I don't know what you call it. It's sort of a mixture of everything, every morning. That's really great for my physical health, it's really great for my mental health, it sort of ties me together as a person, and it allows me to feel, I guess, the same open-mindedness and sense of exhilarated awareness that I felt when I was taking other kinds of psychedelic drugs years ago. But this is true, this is real. This is not something that's chemically induced. This is something that I'm doing. Like I am doing this all myself.

Like Nadia, Callum (M, 36, studying) experienced chronic back pain as the result of an injury and found that daily smoking of cannabis - what he described as 'therapy' for coping with society - alleviated the pain and helped him to relax:

I don't smoke it in the mornings. I wake up, I wait 'til the afternoon, do what I need for the day. Yeah, when I feel the need to relax, when my day's done, I smoke a bit of weed. It helps me unwind. Also when I get to bed at night, due to the fact that I have 
crushed T12 vertebrae, I find that if I don't smoke, I just have problems getting comfortable in bed. But if I do smoke, there's no problems. I'm a basic, normal, functioning human being. Due to my back, when I actually broke it, [the doctors were] like, 'You'll never work, you'll never walk properly again. Here's opiate medication. Take that home'. There was no guidance. There was no nothing, and pardon my French, but I got out of hospital and said, 'Fuck that, I'm a human being. I have rights. I want to live my life. I want to be the best person I can and still be a human basically, and I'm not going to shut myself off'. So I threw out the medication, and just continued to smoke weed through my whole recovery, and I believe it's helped me be a more functional human being. Because there was two avenues I could've gone down. I could've gone down the path of opiate addiction or I can just use cannabis and be a contributing member of society.

Here Callum goes beyond Nadia's account in explicitly expressing the view that his cannabis use is an active force in the achievement of the productivity and participation expected of citizens in contemporary neo-liberal societies. His account also differs from Nadia's in that he rejects the possibility of treating pain with prescribed opioids, preferring cannabis for pain management. He seems to have a much more explicitly critical view of prescription opioids, presenting them as the path to 'addiction', with its associations of dysfunction and social exclusion ('shutting himself off from society'). Cannabis does not hold the same associations for him - he describes himself as capable of consuming cannabis regularly without it disrupting his daily activities.

Other participants described the benefits of their drug use for mental health. For example, John (M, 34, works in health), who described himself as 'dependent on ice [crystal methamphetamine]', had previously experienced psychosis and hospitalisation that he 
attributed to his use of crystal methamphetamine. However, the drug, along with antidepressant medication, was now an active force in the management of his depression:

I guess I still use drugs fairly often. Like I said, I use them as an anti-depressant. On a day-to-day basis, I can feel depressed. That's not to say that I use drugs every day because I don't, but I probably use [them] on average twice a week [...] I'm not sure how they work together, but I take an anti-depressant daily and, like I said, I use crystal [methamphetamine] maybe twice a week. So, you know, I can generally go a couple of days of feeling a bit low, a bit blue, but then I start to feel desperate and want to use again to make me feel better [...] Generally if the drugs are good, I feel less depressed straight away. I feel good, it's a good feeling. I feel confident [...] It's a bit tricky to find that balance [between positive and negative effects...] I guess I don't have a grip on that balance and so I guess that's one reason why I'd like to cut down my use altogether. Not to stop altogether, but to just cut down my use so that I can gain better control over that fine balance.

Zadie, Nadia, Callum and John articulate assemblages in which the consumption of hallucinogens, heroin, prescription opiates, benzodiazepines, cannabis and crystal methamphetamine, respectively, is not positioned as a source of ill-health, disease, pathology, disorder or compulsion. Rather, these drugs are constituted as forces active in the pursuit and achievement of physical and mental health and well-being. More broadly, they may help to create the conditions and capacities required for the fulfilment of neo-liberal citizenship.

\section{'Real addicts'?}

One possible response to the data and analysis we present, already expressed to us following public presentations on material from this project, is that the participants we interviewed are 
not 'real addicts'. As we noted earlier, participants were carefully screened to ensure that they met the criteria for a diagnosis of 'substance use disorder' or 'dependence syndrome'. But what, we also ask, is a 'real addict'? The definition of addiction and the tools used in its diagnosis cover an ever-widening range of states and practices, and have changed markedly, and continue to change, over time (Keane, 2002; Fraser et al., 2014) such that most regular, heavy drug consumption would, at one time or another, or under one diagnostic instrument or another, fall within its purview. For example, in the development of the 'amphetamine dependence syndrome' in the 1990s, the emphasis on daily consumption in order to avoid physical withdrawal, so central to earlier definitions of alcohol and heroin addiction, was deemphasised in favour of psychological 'compulsion' and 'binges', thus allowing greater numbers of people to be pathologised as 'dependent' (Fraser et al., 2014:65-76). Similarly, in a clear case of 'diagnostic bracket creep', the changes introduced in the DSM-5 expanded the category of addiction so that a new set of people and practices were brought within the 'substance use disorder' category (Fraser et al., 2014:36). In this system, meeting any four of the 11 criteria is sufficient to confirm a moderately severe disorder, meaning that two people diagnosed with the condition may not share a single symptom (Fraser et al., 2014:45).

The major international tools currently being used to screen for and diagnose 'addiction' (or dependence or disorder) have also been the subject of recent critique. Dwyer and Fraser (2015) deconstruct the validation processes used to establish the legitimacy of addiction screening and diagnostic tools as well as question their claims to independence and objectivity. In a related analysis, the same authors interrogate the logics and assumptions of such tools and argue that they "work to establish, standardise and reify addiction as an independent, pre-existing affliction located in individuals' (Dwyer \& Fraser, 2016:1). In so doing, they argue, they 'erase the complexities and subjective interpretations of individual 
experiences' (Dwyer \& Fraser, 2016:1) that have been our primary focus here. Indeed, the view that the 'addiction' category is fundamentally pathologising, and that it serves to 'erase the complexities and subjective interpretations of individual experiences' (Dwyer \& Fraser, 2016:1), was articulated by one of the participants interviewed for our project:

['Addiction'] seems to be one of these things that we'll just bend and twist and make fit whatever we might be discussing, challenging, restricting, at that time. Or again, demonising, using [it] as a stick to hit people over the head with, and that's the way I see a word like 'addiction' $[\ldots]$ It's a loaded term $[\ldots]$ and depending on $[\ldots]$ your understanding of that word, or how it's used by whoever, chasing whatever agenda, then that word will have a different meaning for you [...] So I don't find [a] word like 'addiction' very useful and now it's been applied to so many things, and we're just talking about people's behaviours, which aren't easily defined and can't be put into a word so simply. (Harry, M, 52)

Labelling the interview participants as not 'real addicts', it seems to us, returns us to the formulation offered by Fraser et al. (2014): what is 'addiction' if not an unstable assemblage made in practice, multiple and contingent, its shape, scale and content dependent upon a range of other equally labile phenomena?

\section{Conclusion}

In this article, we have explored the relationship between addiction, health and well-being in the accounts offered by participants self-identifying as experiencing an addiction, dependence or habit. Whereas some participant descriptions of the relationship between addiction, health and well-being reinscribe the binary opposition found in science, policy and popular assemblages of addiction, others offer more complex accounts in which addiction, health and well-being are assembled together. These latter accounts include those in which participants 
assembled strategies for managing or supporting their physical and mental health alongside their use of alcohol and other drugs, and those in which consumption is constituted in the assemblage as a force active in the maintenance of health and well-being.

If, as we argued above, the claim that the participants in our study are not 'real addicts' is unsustainable, what else might be concluded on the basis of their accounts of the complex relationship between addiction, health and well-being? We return to the characterisation with which we opened the article: that scientific, policy and popular assemblages, all crucial elements of the 'epidemic of addicting' underway in contemporary neo-liberalism, constitute addiction as antithetical to health and well-being. One of the ways in which these addicting discourses achieve this polarity is by evacuating from the category of 'addiction' those who care for their health while also using drugs heavily and regularly - that is, in ways likely to attract a diagnosis of 'addiction' in current screening tools. Our choice of the word 'evacuation' here is carefully considered for its connotations of removal from a place or state of danger, in this case addiction. This evacuation functions to preserve disease and pathology as the hallmarks of addiction. Conversely, treatment and recovery regimes and popular discourse routinely excise 'addiction' from definitions of 'health' and 'well-being'. Again, our choice of term is specific. The medical metaphor 'excise' is deliberate in that it references the total removal of diseased tissue that threatens the healthy body. In these accounts, being healthy requires the cessation, the removal, of alcohol and other drug use.

The participant accounts raise significant challenges to the addicting so prevalent in contemporary science, policy and popular assemblages. First, they remind us that addiction is a complex assemblage made up of many mutually constitutive phenomena: substance, patterns of use, gender, sexuality, geography, occupation, social conduct, resources, social 
relationships, stage of life, family obligations and state intervention. To this list we must add strategies for achieving health and well-being, and the active role of drugs in the pursuit and achievement of physical and mental health and well-being, and even of neo-liberal citizenship. While it is not our intention to idealise or endorse the many elements offered in these accounts, the social forces and processes they describe are indispensable to discussions of the meaning of addiction. Addiction is not singular and nor is health. To stabilise addiction as antithetical to health and well-being is to exclude from its ontology much that is - at any given moment, for different people and under varying conditions - actually part of it.

Finally, what would policy and practice look like if assemblages of addiction, health and well-being were taken seriously? Recognising that 'addiction' and health can be generated within the same assemblages may allow for more nuanced, effective responses that do not treat consumption as necessarily inimical to health. Policy and practice may aim to provide resources that support and enable people who regularly consume alcohol and other drugs to maintain their health and well-being, without the potentially alienating injunction that they must renounce consumption in order to do so. While, for some of our participants, reducing or avoiding consumption altogether was seen as necessary to achieve or maintain health, others emphasised the role of consumption in the relational achievement of health and wellbeing. Where both addiction and health assemblages may share forces and resources in common, the question for policy and practice becomes: how might these assemblages be mobilised in such a way that health and well-being can become a greater part, or effect, of consumption practices? Considering addiction/health assemblages offers fertile ground for rethinking the strengths and capacities of those who self-identity as living with an addiction, dependence or habit, as well as untapped resources for responding to the harm that can be associated with alcohol and other drug use. 


\section{Appendix 1}

Table: Participant characteristics $(\mathrm{N}=60)$

\begin{tabular}{|c|c|}
\hline Gender $^{\wedge}$ & Number \\
\hline Men & 35 \\
\hline Women & 25 \\
\hline \multicolumn{2}{|l|}{ Main preferred drug* } \\
\hline Alcohol & 11 \\
\hline Cannabis & 14 \\
\hline Opiates & 14 \\
\hline Stimulants & 12 \\
\hline 'Party drugs' (e.g. MDMA, GHB, Ketamine) & 4 \\
\hline Prescription and over-the-counter drugs & 5 \\
\hline \multicolumn{2}{|l|}{ Age } \\
\hline $18-29$ & 14 \\
\hline $30-39$ & 20 \\
\hline $40-49$ & 14 \\
\hline $50+$ & 12 \\
\hline \multicolumn{2}{|l|}{ Cultural and ethnic background } \\
\hline Australian & 31 \\
\hline Australian Aboriginal & 2 \\
\hline New Zealander & 1 \\
\hline Polynesian & 2 \\
\hline North-West European & 12 \\
\hline Southern and Eastern European & 4 \\
\hline North African and Middle Eastern & 1 \\
\hline South-East Asian & 1 \\
\hline North-East Asian & 2 \\
\hline North American & 2 \\
\hline Southern and Eastern African & 2 \\
\hline \multicolumn{2}{|l|}{ Sexual identity } \\
\hline Heterosexual & 41 \\
\hline LGBTIQ+ & 18 \\
\hline Unspecified & 1 \\
\hline \multicolumn{2}{|l|}{ Education level } \\
\hline Secondary & 26 \\
\hline Post-secondary & 12 \\
\hline Tertiary & 22 \\
\hline \multicolumn{2}{|l|}{ Employment status } \\
\hline Working/studying & 41 \\
\hline Not working/studying & 19 \\
\hline \multicolumn{2}{|l|}{ Location } \\
\hline Major urban - Victoria: Melbourne & 21 \\
\hline Regional - Victoria: Bendigo & 9 \\
\hline Major urban - New South Wales: Sydney & 19 \\
\hline Regional - New South Wales: Byron Bay, Lismore \& Nimbin & 11 \\
\hline
\end{tabular}

$\wedge$ All participants identified either as male or female. 
* Some participants described consuming only one drug, while others talked about two or more. The table lists the drug that participants identified as their primary preferred drug.

$\sim$ Reporting of cultural and ethnic background follows the Australian Standard Classification of Cultural and Ethnic Groups, developed by the Australian Bureau of Statistics. Cultural and ethnic background was classified according to a combination of self-reported group identification with particular cultural or ethnic groups, the participant's birthplace and their parents' birthplaces.

\section{References}

American Psychiatric Association. (2013). Diagnostic and Statistical Manual of Mental Disorders, fifth edition. Washington DC: American Psychiatric Press.

Burrows, R., Nettleton, S., \& Bunton, R. (1995). Sociology and health promotion: Health, risk and consumption under late modernism. In R. Bunton, S. Nettleton, \& R. Burrows (Eds.), The sociology of health promotion: Critical analyses of consumption, lifestyle and risk (pp. 1-12). London and New York: Routledge.

Crawford, R. (1977). You are dangerous to your health: The ideology and politics of victim blaming. International Journal of Health Services, 7(4), 663-680.

Crawford, R. (1994). The boundaries of the self and the unhealthy other: Reflections on health, culture and AIDS. Social Science and Medicine, 38(10), 1347-1365.

Crawford, R. (2006). Health as a meaningful social practice. Health, 10(4), 401-420.

Duff, C. (2014). Assemblages of health: Deleuze's empiricism and the ethology of life. Dordrecht: Springer.

Dumit, J. (2004). Picturing personhood: Brain scans and biomedical identity. Durham: Durham University Press.

Dwyer, R., \& Fraser, S. (2015). Addiction screening and diagnostic tools: 'Refuting' and 'unmasking' claims to legitimacy. International Journal of Drug Policy, 26(12), 1189 1197.

Dwyer, R., \& Fraser, S. (2016). Making addictions in standardised screening and diagnostic tools. Health Sociology Review, 25(3), 223-239. 
Farrugia, A. (2015). 'You can't just give your best mate a massive hug every day': Young men, play and MDMA. Contemporary Drug Problems, 42(3), 240-256.

Fraser, S., \& Moore, D. (2008). Dazzled by unity? Order and chaos in public discourse on illicit drug use. Social Science and Medicine, 66, 740-752.

Fraser, S., \& Moore, D. (2011). Governing through problems: The formulation of policy on amphetamine-type stimulants (ATS) in Australia. International Journal of Drug Policy, 22(6), 498-506.

Fraser, S., Moore, D., \& Keane, H. (2014). Habits: Remaking addiction. Basingstoke and New York: Palgrave Macmillan.

Fraser, S., \& Seear, K. (2011). Making disease, making citizens: The politics of hepatitis $C$. Ashgate: Aldershot.

Fraser, S., \& valentine, k. (2008). Substance and substitution: Methadone subjects in liberal societies. Palgrave Macmillan, Basingstoke.

Fry, C., \& Dwyer, R. (2001). For love or money? An exploratory study of why injecting drug users participate in research. Addiction, 96(9), 1319-25.

Hart, A. (2015). Assembling interrelations between low socioeconomic status and acute alcohol-related harms among young adult drinkers. Contemporary Drug Problems, $42(2), 148-167$.

Health Experiences Research Group (HERG). (2010). Researcher's handbook for producing HealthTalkOnline and YouthHealthTalk websites. Oxford: Health Experiences Research Group, Oxford University.

Keane, H. (2000). Setting yourself free: techniques of recovery. Health, 4(3), 324-346.

Keane, H. (2002). What's wrong with addiction? Melbourne: Melbourne University Press. 
Kirkland, A. (2010). Conclusion: What next? In J.M. Metzl, \& A. Kirkland (Eds.), Against health: How health became the new morality (pp. 195-203). New York: New York University Press.

Levine, H.G. (1978). The discovery of addiction: Changing conceptions of habitual drunkenness in America. Journal of Studies on Alcohol, 39(1), 143-174.

Lupton, D. (1995). The imperative of health: Public health and the regulated body. London: Sage.

McLeod, K. (2014). The missing work of collaboration: Using assemblages to rethink antidepressant action. Contemporary Drug Problems, 41(1), 109-142.

Metzl, J.M. (2010). Introduction: Why 'against health'? In J.M. Metzl, \& A. Kirkland (Eds.), Against health: How health became the new morality (pp. 1-11). New York: New York University Press.

Moore, D. (2004). Governing street-based injecting drug users: A critique of heroin overdose prevention in Australia. Social Science and Medicine, 59(7), 1547-1557.

Moore, D., \& Fraser, S. (2006). Putting at risk what we know: Reflecting on the drug-using subject in harm reduction and its political implications. Social Science and Medicine, 62, 3035-3047.

O’Malley, P. (1999). Consuming risks: Harm minimization and the government of 'drug users'. In R. Smandych (Ed.), Governable places: Readings in governmentality and crime control (pp. 191-214). Aldershot: Dartmouth.

Petersen, A. (1997). Risk, governance and the new public health. In A. Petersen, \& R. Bunton (Eds.), Foucault, health and medicine (pp. 188-206). London and New York: Routledge.

Petersen, A., \& Bunton, R. (Eds.) (1997). Foucault, health and medicine. London, New York: Routledge. 
Petersen, A., \& Lupton, D. (1996). The new public health: Health and self in the age of risk. St. Leonards: Allen and Unwin.

Pienaar, K. (2016). Claiming rights, making citizens: HIV and the performativity of biological citizenship. Social Theory \& Health, 14(2), 149-168.

Race, K. (2014). Complex events: Drug effects and emergent causality. Contemporary Drug Problems, 41(3), 301-334.

Redfield, M., \& Brodie, J.F. (2002). Introduction. In High anxieties: Cultural studies in addictions (pp. 1-15). Berkeley: University of California Press.

Reinarman, C. (2005). Addiction as an accomplishment: The discursive construction of disease. Addiction Research and Theory, 13(4), 307-320.

Reith, G. (2004). Consumption and its discontents. British Journal of Sociology, 55(2), 283300.

Room, R. (1985). Dependence and society. British Journal of Addiction, 80(2), 133-139.

Room, R. (2003). The cultural framing of addiction. Janus Head, 6(2), 221-234.

Seddon, T. (2010). A history of drugs: Drugs and freedom in the liberal age. London: Routledge.

Sedgwick, E.K. (1994). Epidemics of the will. In Tendencies (pp. 130-142). London: Routledge.

Squire, C. (2010) Being naturalised, being left behind: The HIV citizen in the era of treatment possibility. Critical Public Health, 20(4), 401-427.

Tesh, S.N. (1990). Hidden arguments: Political ideology and disease prevention policy. New Brunswick: Rutgers University Press.

Volkow, N., \& Li, T. (2004). Drug addiction: The neurobiology of behaviour gone awry. Nature Reviews Neuroscience, 5, 963-970. 
Weinberg, D. (2011). Sociological perspectives on addiction. Sociology Compass, 5(4), 298310.

World Health Organization. (1992). The ICD-10 Classification of Diseases and Related Health Problems. Geneva: World Health Organization. 